\title{
Low-frequency radar sounding of ice in East Antarctica and southern Greenland
}

\author{
J. MOUGINOT, ${ }^{1}$ E. RIGNOT, ${ }^{1,2}$ Y. GIM, ${ }^{2}$ D. KIRCHNER, ${ }^{3}$ E. LE MEUR ${ }^{4,5}$ \\ ${ }^{1}$ Department of Earth System Science, University of California Irvine, Irvine, CA, USA \\ E-mail: jmougino@uci.edu \\ ${ }^{2}$ Jet Propulsion Laboratory, California Institute of Technology, Pasadena, CA, USA \\ ${ }^{3}$ Department of Physics and Astronomy, University of lowa, lowa City, IA, USA \\ ${ }^{4}$ Laboratoire de Glaciologie et Géophysique de l'Environnement, CNRS, Grenoble, France \\ ${ }^{5}$ Laboratoire de Glaciologie et Géophysique de l'Environnement, Univ. Grenoble Alpes, Grenoble, France
}

\begin{abstract}
We discuss a decameter-wavelength airborne radar sounder, the Warm Ice Sounding Explorer (WISE), that provides ice thickness in areas where radar signal penetration at higher frequencies is expected to be limited. Here we report results for three campaigns conducted in Greenland (2008, 2009, 2010) and two in Antarctica $(2009,2010)$. Comparisons with higher-frequency radar data indicate an accuracy of $\pm 55 \mathrm{~m}$ for ice-thickness measurements in Greenland and $\pm 25 \mathrm{~m}$ in Antarctica. We also estimate ice thickness of the Qassimiut lobe in southwest Greenland, where few ice-thickness measurements have been made, demonstrating that WISE penetrates in strongly scattering environments.
\end{abstract}

KEYWORDS: Antarctic glaciology, ground-penetrating radar, radio-echo sounding, remote sensing

\section{INTRODUCTION}

The current and future contributions to sea-level change from ice masses around the world remain difficult to estimate, due to the limited availability of ice-thickness data (e.g. Jacob and others; 2012). Efficient, airborne icethickness and/or bed-topography data are needed to estimate fluxes of outlet glaciers into the ocean, the total volume of ice left in drainage basins, and its partitioning above and below sea level. High-frequency $(>50 \mathrm{MHz})$ radar sounders are routinely used to map ice thickness, detect internal layers and provide information about basal conditions (Gogineni and others, 2001). A large number of airborne campaigns have been conducted in Greenland and Antarctica over the last decade, especially under NASA's Operation IceBridge (OIB) (Studinger and others, 2010) using, among others, the Multichannel Coherent Radar Depth Sounder (MCoRDS) from the Center for Remote Sensing of Ice Sheets (CReSIS) (Gogineni and others, 2001; Allen, 2010; Rodriguez-Morales and others, 2013) and the High-Capability Radar Sounder (HiCARS) from the University of Texas at Austin (Blankenship and others, 2011; Young and others, 2011). MCoRDS and HiCARS operate at bandwidths of $140-210$ and $52.5-67.5 \mathrm{MHz}$, respectively. Comprehensive ice-thickness maps of Greenland and Antarctica have been produced using data from these and other systems (Bamber and others, 2013; Fretwell and others, 2013), yet significant gaps exist, in particular at the coastline and along deep channels occupied by outlet glaciers. An electromagnetic wave propagating in ice (a dielectric medium) loses its signal strength to geometric spreading, absorption, volume scattering and high surface and bottom scatter. Volume scattering depends strongly on radar frequency and the presence of liquid water. Regions containing englacial channels, fractures and crevasses, either drained or containing liquid water, create scatter (Smith and Evans, 1972; Arcone, 2002; Catania and Neumann, 2010). Rayleigh-scattering theory suggests that when the scatterers are smaller than the radar wavelength, scattering losses are inversely proportional to the fourth power of the radar wavelength (Ishimaru, 1978), so the sounding of such regions has proven difficult for radar sounders operating at $>50 \mathrm{MHz}$ (Smith and Evans, 1972; Watts and England, 1976; Watts and Wright, 1981).

In Alaska or Patagonia, where ice is at the melting point throughout the ice column (Molnia, 2008), only radars operating below $5 \mathrm{MHz}$ have been used to retrieve ice thickness (Brown and others, 1986; Jacobel and Anderson, 1987; Raymond and others, 2005; Conway and others, 2009; Gades and others, 2012).

In Greenland, especially along the southern coasts, moulins (Catania and Neumann, 2010), englacial conduits (Catania and others, 2008), supraglacial lakes (McMillan and others, 2007) and water-filled crevasses (Lampkin and others, 2013) are commonly found below the equilibriumline altitude (ELA), attesting to the presence of liquid water, and may limit the ability of the higher-frequency radars to detect the bed interface by creating a strong scattering environment.

Based on previous successes with ground-based lowfrequency radar, we have developed, since 2006, a decameter-wavelength airborne radar sounder $(1-5 \mathrm{MHz})$, the Warm Ice Sounding Explorer (WISE), that is designed to measure ice thickness in areas where radar signal penetration is limited at higher frequencies. In another paper, we reported results obtained in Alaska that demonstrate the full capacity of the system over temperate ice, with ice-thickness measurements exceeding $1200 \mathrm{~m}$ and bed returns obtained both in the ablation and accumulation areas of all surveyed glaciers (Rignot and others, 2013a).

In this paper, we provide a succinct description of the system and the radar data. We then give details of three campaigns conducted in southern Greenland in 2008, 2009 and 2010, and two in East Antarctica in 2009 and 2010. We compare radar profiles from MCoRDS and WISE in the extreme south of Greenland, which is likely to be a scattering environment. Finally, to assess the accuracy of 


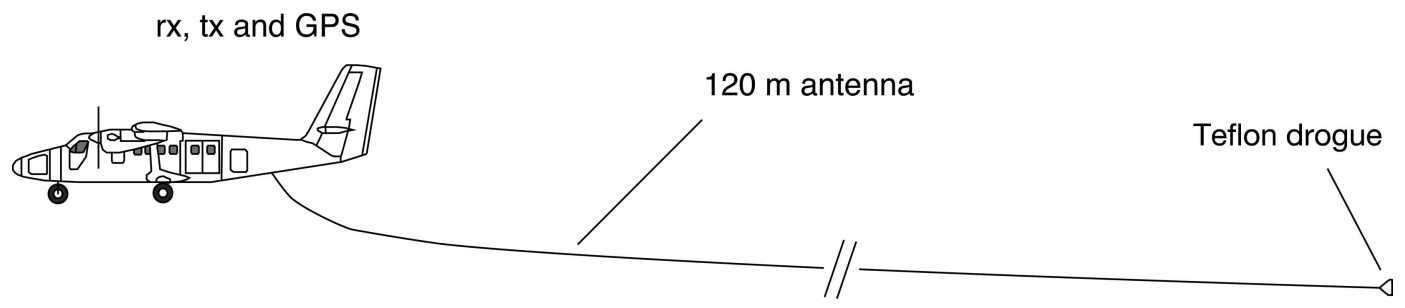

Fig. 1. Configuration used for airborne radio sounding with WISE. The transmitter (tx), receiver ( $r x$ ) and GPS are on-board the airplane. A drogue was attached to the end of the antenna. The antenna behaves like a dipole by using the aircraft as a ground plane.

our ice-thickness mappings, we compare the results with higher-frequency radar data acquired at two sites with dense grid surveys, one in Greenland and one in Antarctica, hence representative of both scattering and highly penetrative environments. We conclude by discussing the impact of WISE radar sounding in improving our knowledge of ice thickness and bed topography.

\section{DATA AND METHODS}

\section{Instrument design}

The WISE radar hardware was originally developed as a proof-of-concept system for an ice-penetrating radar to explore Jupiter's icy moons: Europa, Ganymede and Callisto. It is based on a prior design of the Mars Advanced Radar for Subsurface and lonosphere Sounding (MARSIS) (Picardi and others, 2005), which was designed to penetrate the Martian subsurface to depths of up to $4 \mathrm{~km}$ in ice-rich polar layered deposits, and up to several hundreds of meters in lithic environments (Plaut and others, 2007; Mouginot and others, 2010, 2012).

The radar consists of a digital system with a GPS interface, a radio-frequency (RF) receiver, an RF transmitter with matching network and an antenna (Fig. 1). The transmitter, the key component of WISE, was developed under the NASA Planetary Instruments Definition and Development Program (PIDDP) with requirements including radiation tolerance, small size and high efficiency. The design is based on the MARSIS transmitter built by the University of lowa. The antenna is constructed inside a $120 \mathrm{~m}$ long static rope. Electrically, it is heavily damped to minimize ringing, which allows operation at low altitudes and a wide frequency range of $1-5 \mathrm{MHz}$, at the expense of a reduced radiated power of $<1 \mathrm{~W}$. Due to its long length, the antenna is released and retracted in the air via a small opening in the aircraft floor. To lower the antenna below the aircraft belly, a Teflon drogue and counterweight is attached to the end of the antenna, to maintain a shallow antenna angle of $\sim 30^{\circ}$ in flight. This allows the antenna to stay away from the aircraft fuselage. The antenna coupler drives the resistively loaded wire antenna against the airplane structure. The antenna behaves like a dipole, using the aircraft as a ground plane, and its design was optimized using a Nippon Electronic Company computer model simulation by the University of lowa to maximize coupling with the transmitter/receiver.

The RF receiver is a commercial Ritec broadband receiver, BR-640A, with a frequency range of $100 \mathrm{kHz}$ to $50 \mathrm{MHz}$. The analog signal output of the receiver is connected via a coaxial cable to the input of a 12-bit analog-to-digital converter (A/D) in a National Instruments data acquisition computer. The A/D runs at $100 \mathrm{MHz}$. After on-board pre-summing of 14 -fold, the data are stored into
16 bits on the computer disk, in sequences of 20 min of acquisition. A conventional GPS receiver is operated at $20 \mathrm{~Hz}$ along with the radar, with a vertical precision of $\sim 20 \mathrm{~m}$. The total mass, including the mounting rack for the transmitter and receiver, is $\sim 50 \mathrm{~kg}$. The power consumption of the system is $<100 \mathrm{~W}$.

WISE transmits tone or chirp waveforms at a pulse repetition frequency (PRF) of $1 \mathrm{kHz}$ (Table 1). The tone mode uses a single continuous-wave pulse centered at $2.5 \mathrm{MHz}$ for a duration of $1 \mu \mathrm{s}$ (Fig. 2). The chirp mode transmits a linear FM chirp centered between 2 and $5 \mathrm{MHz}$ over a bandwidth of $1-3 \mathrm{MHz}$ for a duration of 3-6 $\mu$ s (Fig. 3).

Radar command parameters (e.g. PRF, center frequency, waveform (tone or chirp) and sampling rate) are controlled using a Labview code, and may be changed at any time with a small time gap between command updates. With on-board processes (e.g. range compression and pre-summing), WISE displays radar echograms in real time. This allows the operator to monitor bed returns during flight and adjust radar parameters accordingly.

We recorded at altitudes between $250 \mathrm{~m}$ and $1 \mathrm{~km}$ above the surface. Lower altitudes increase spatial resolution, reduce surface clutter and clip radar returns from the surface. When the altitude is low, surface incidence angles toward off-nadir targets increase and signals rapidly weaken. Clipping of the surface returns also limits the saturation of the receiver, which results in a higher signal-to-noise ratio of the bed returns.

\section{Processing}

For chirp signals, post-processing begins with range compression using a transmitted waveform as the reference (Fig. 3). Incoherent summation or fully focused synthetic

Table 1. Typical operating parameters for WISE. Measurement depth for Alaska is from Rignot and others (2013a)

Parameter Value

Excitation (chirp waveform)
Center frequency
Bandwidth
Pulse repetition frequency
Pulse duration
Antenna length
Antenna gain
Receiver gain
Operational altitude
Measurement depth

Tone or chirp
$2-5 \mathrm{MHz}$
$1-3 \mathrm{MHz}$
$1 \mathrm{kHz}$
$1-5 \mu \mathrm{s}$
$120 \mathrm{~m}$
$0 \mathrm{~dB}$
$20-40 \mathrm{~dB}$
$250-1000 \mathrm{~m}$
$<1.2 \mathrm{~km}$ (Alaska)
$<2.2 \mathrm{~km}$ (Greenland)
$<3.5 \mathrm{~km}$ (Antarctica)



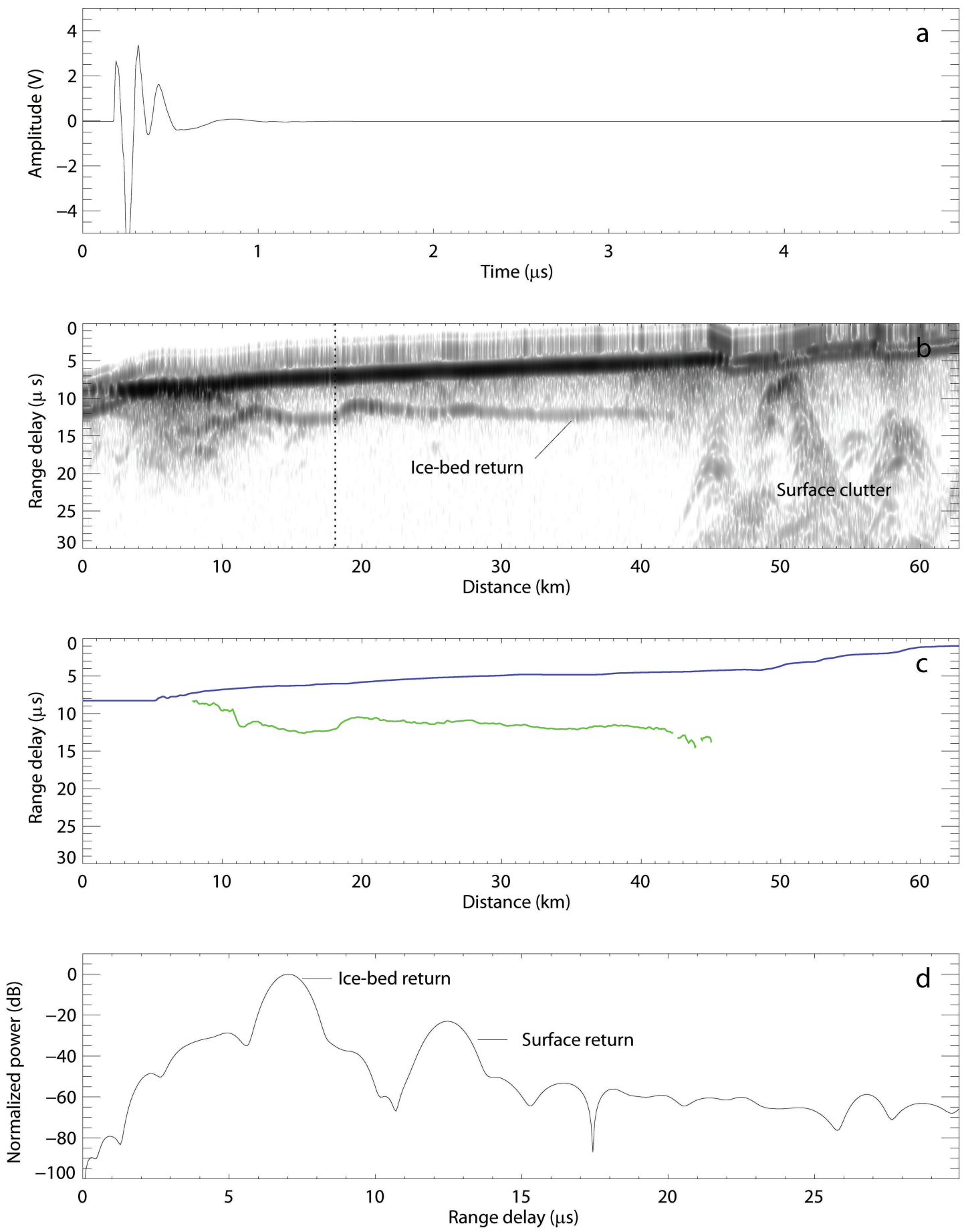

Fig. 2. (a) Transmitted tone waveform at $2.5 \mathrm{MHz}$. (b) Echo-radargram acquired in southern Alaska. A background removal filter has been applied. (c) The blue and green lines represent the surface position from the lidar scanner of NASA's OIB (Johnson and others, 2013; Rignot and others, 2013a) and the hand-picked bed from (b), respectively. (d) Received signal (after pulse compression) at the position indicated by the dashed line in (b).

aperture radar (SAR) processing using a $\omega-k$ migration algorithm (Stolt, 1978) follows, depending on surface roughness and track length. GPS data are also processed into Google Keyhole Markup Language $(\mathrm{kml})$ format so each track can be displayed on Google Earth.

The echo profiles are manually digitized to delineate the glacier bed in three steps: (1) the bed is roughly defined by a user using a few 'anchor points', where the bed return is unambiguously identified; (2) the maximum intensity along the lines that connect these anchor points is used to set the bed position along track (see Figs 2 and 3); (3) this digitized glacier bed echo is checked at crossing points with other tracks or other datasets to limit the possibility of false detection (e.g. due to off-nadir radar reflections), which is generally not an issue in Greenland and Antarctica, where the surface is flat compared to mountainous regions, such as Alaska or Patagonia.

WISE is often operated at low altitudes above the surface, hence clipping the surface returns. The surface references needed to measure ice thickness are from the Greenland Ice Mapping Project (GIMP) digital elevation model (DEM; http://bprc.osu.edu/GDG/gimpdem.php) and from the $1 \mathrm{~km}$ DEM that combines European Remote-sensing Satellite (ERS-1) radar and Ice, Cloud and land Elevation Satellite 

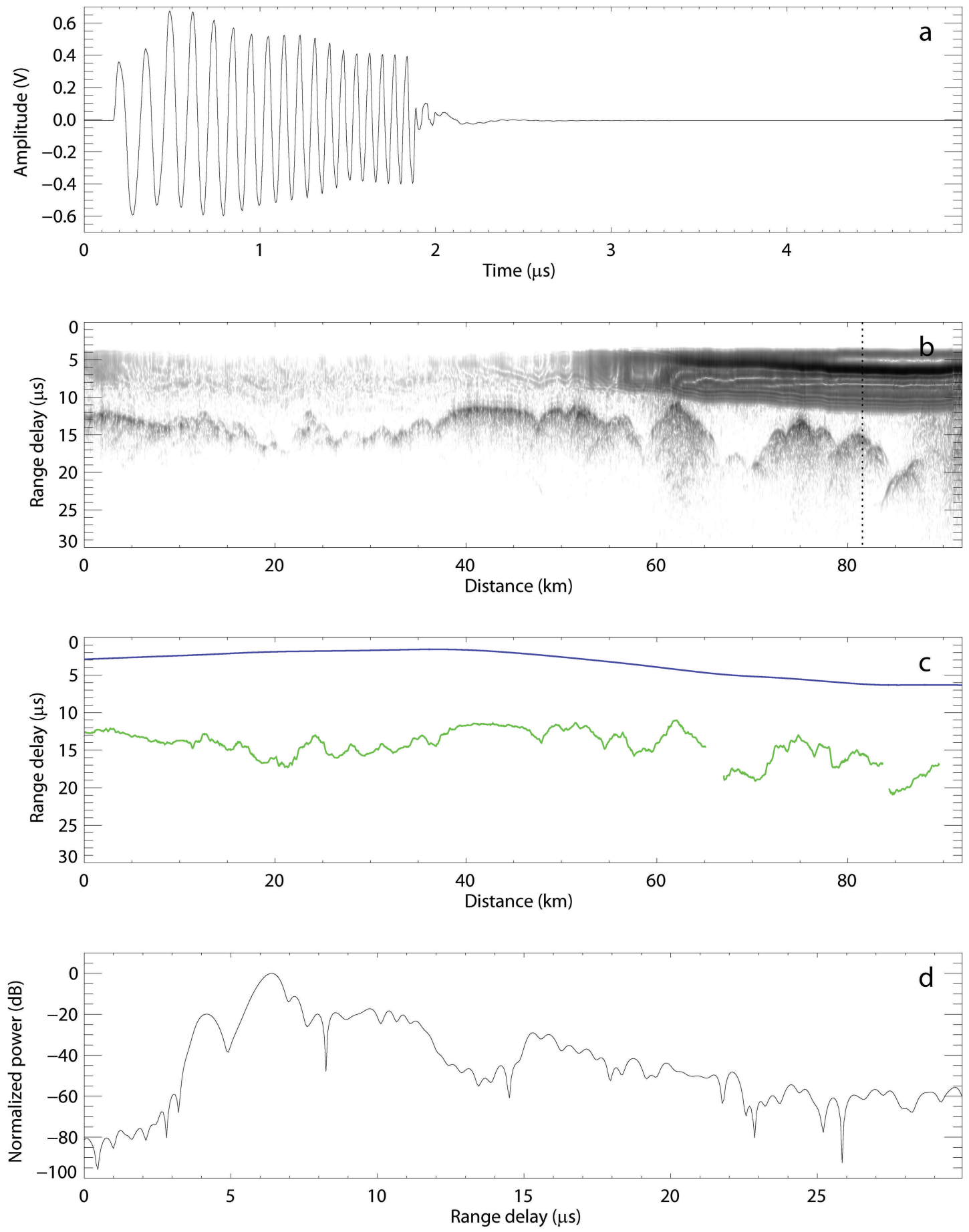

Fig. 3. (a) Transmitted chirp waveform between 2 and $5 \mathrm{MHz}$. (b) Echo-radargram obtained after range compression. Data acquired in East Antarctica. Surface is truncated between distances 0 and $60 \mathrm{~km}$ because the data were acquired at low altitudes. (c) The blue and green lines represent the surface position from Bedmap2 (Fretwell and others, 2013) and the hand-picked bed from (b), respectively. (d) Received signal (after pulse compression) at the position indicated by the dashed line in (b).

(ICESat) laser satellite altimetry (Bamber and others, 2009; Griggs and Bamber, 2009).

\section{ICE-THICKNESS MEASUREMENTS}

\section{Greenland}

We conducted three surveys in Greenland with WISE in May 2008, April 2009 and March 2010, using a Twin Otter aircraft from Air Greenland with a total of 18, 37 and 35 hours of survey, respectively. Most of the flight lines are within $100 \mathrm{~km}$ of the Greenland ice sheet margins, i.e. where output ice fluxes to the ocean are most conveniently estimated, most heavily crevassed and the ice likely contains liquid water.

In terms of maximum penetration depth, we recorded bed reflections through $2.2 \mathrm{~km}$ of ice across the ice sheet between Russell Glacier and Kangerlussuaq Glacier (Fig. 4). We observed that the signal-to-noise ratio decreases toward southern Greenland, where ice is exposed to the highest air temperatures, and hence the highest amount of liquid water within the ice (Box and others, 2006; Sundal and others, 2009). The southernmost area of Greenland, which ends with the $100 \mathrm{~km}$ wide Qassimiut lobe, is drained 


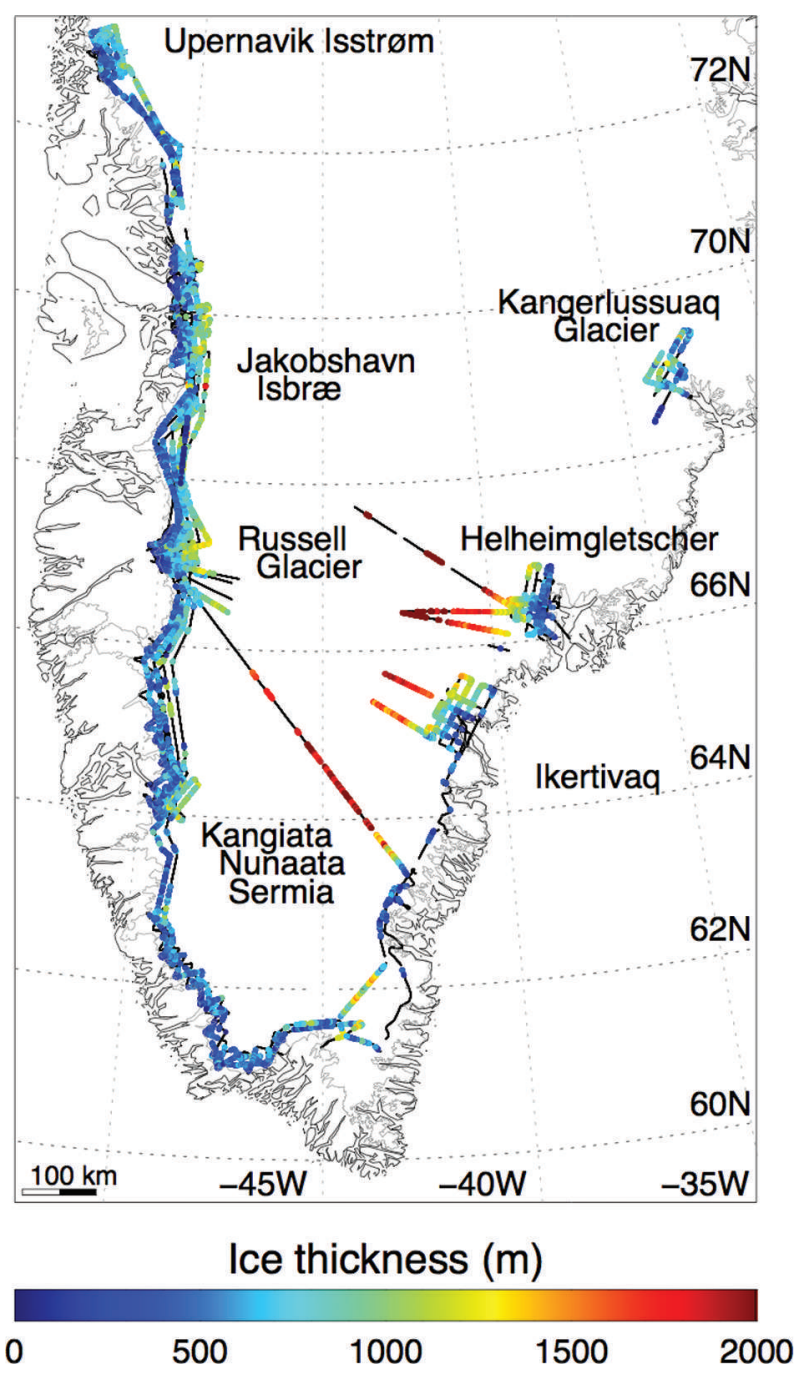

Fig. 4. Ice thickness of southern Greenland from WISE during surveys conducted in 2008, 2009 and 2010. Data in black indicate no bed return. Thin gray and black lines represent, respectively, the ice edge (http://bprc.osu.edu/GDG/icemask.php) and the coastline (Rignot, 2012).

by tidewater glaciers that include Qajuuttap Sermia, Sermilik and Eqalorutsit Killiit Sermiat, and land-terminating glaciers, such as Søndre Qipisaqqu Bræ and Arsuk Bræ.

In the Qassimiut lobe sector, data acquired in May 2013, June 2006, May 2010, April 2012 and March 2013 by MCoRDS radar $(>150 \mathrm{MHz})$ provide good measurements of ice thickness $\sim 50-150 \mathrm{~km}$ from the ice-sheet margins (Fig. 5), and gradually degrade as the margins are approached. Thus, few ice-thickness measurements have been made in the southern part of the Qassimiut lobe, where bed topography has remained largely undocumented. WISE, which flew within $50 \mathrm{~km}$ of the ice margins of the Qassimiut lobe, obtained relatively good ice-thickness data over 50\% of the flight lines flown. We define 'good' to mean that the signal-to-noise ratio for the bedrock echo is $>10 \mathrm{~dB}$.

Figure 6 compares two echo-radargrams from WISE (Fig. 6b) and MCoRDS (Fig. 6c) acquired along similar flight lines on 22 March 2010 and 9 May 2003, respectively. An ice-bed return (yellow line) is visible on the $2-5 \mathrm{MHz}$ echogram from 3 to $15 \mathrm{~km}$ starting at a depth of $150 \mathrm{~m}$ and reaching depths of $700 \mathrm{~m}$, where no signal is visible within the MCoRDS echogram. The surface of this particular region is very flat, so confusion between surface and ice-bed returns leading to misinterpretation is unlikely. MCoRDS data were generally acquired later in the season, and the lack of return could also be explained by the presence of substantial surface melt. However, we observe that recent acquisitions on 8 April 2013, only 2 weeks later in the season than WISE, did not yield better results.

Ice thickness measured by WISE in the Qassimiut lobe (Fig. 6) is $300-400 \mathrm{~m}$, with local depressions in bed topography in the front of Arsuk Bræ $(580 \mathrm{~m})$, Søndre Qipisaqqu Bræ $(910 \mathrm{~m})$, Sermilik Bræ $(710 \mathrm{~m})$ and Eqalorutsit Killiit Sermiat (1100 m).

Along the southwest coast of Greenland, near Kangerlussuaq town (Fig. 4), an intensive grid was acquired in 2010 over Russell Glacier with a track spacing of $3 \mathrm{~km}$. NASA OIB/MCORDS conducted a similar survey over the glacier, also in 2010, with a track spacing of $500 \mathrm{~m}$. This test site (Fig. 8c) is used to evaluate the accuracy of WISE in Greenland.

\section{Antarctica}

We deployed WISE in East Antarctica (Fig. 7) for 35 and 29 hours in January 2009 and January 2010, respectively. The platform used for deployment was a Twin Otter aircraft from Kenn Borek Air Ltd, Canada, in 2009, and a Kenn Borek 'Basler' DC3 aircraft in 2010. In 2009, we surveyed Byrd, Dibble, Mertz, David and Astrolabe glaciers in East Antarctica. In 2010, we surveyed Frost, Mertz and Astrolabe glaciers and the Cook Ice Shelf with both WISE and HiCARS radar. On both deployments, the survey of Astrolabe and Mertz Glaciers was performed in collaboration with the Laboratoire de Glaciologie et Géophysique de l'Environnement, France, with logistic support from the US National Science Foundation and the Institut Paul-Emile Victor.

Close to the French station Dumont d'Urville, Terre Adélie, two intensive grids were surveyed over Astrolabe Glacier in January 2009 and complemented by additional data in January 2010. These data resulted in a $5 \mathrm{~km}$ grid of the lower basin, degrading to $20 \mathrm{~km}$ in the upper part, but producing a complete survey of the entire drainage basin, probably a unique achievement in Antarctica. The drainage basin of Astrolabe Glacier extends $\sim 200 \mathrm{~km}$ inland and its area is $\sim 1500 \mathrm{~km}^{2}$. The bed of Astrolabe Glacier is near sea level and ends by a partially floating ice tongue that is $\sim 8 \mathrm{~km}$ long and $600 \mathrm{~m}$ thick. This test site is used to evaluate the accuracy of WISE in Antarctica discussed in the following subsection.

\section{Measurement accuracy}

The theoretical vertical resolution of the $2.5 \mathrm{MHz}$ WISE data is one-quarter of the wavelength, or $30 \mathrm{~m}$ in air and $17 \mathrm{~m}$ in ice. We assume a constant dielectric permittivity of 3.15 for ice and do not apply a snow/firn correction. In snowcovered regions, this means that ice thickness may be slightly underestimated, whereas in wet or 'dusty' ice regions, ice thickness may be slightly overestimated. Typically, the ice dielectric constant from field and laboratory measurements ranges from 3.0 to 3.25 (Bogorodsky and others, 1985; Macheret and others, 1993), which corresponds to $\pm 2 \%$ of the ice thickness or $\pm 20 \mathrm{~m}$ for ice $1000 \mathrm{~m}$ thick. Another source of uncertainty is in the precision of the position of the airplane from GPS $(\sim 20 \mathrm{~m})$. As we usually use a surface elevation reference from an external DEM, additional uncertainties from these reference surfaces must 


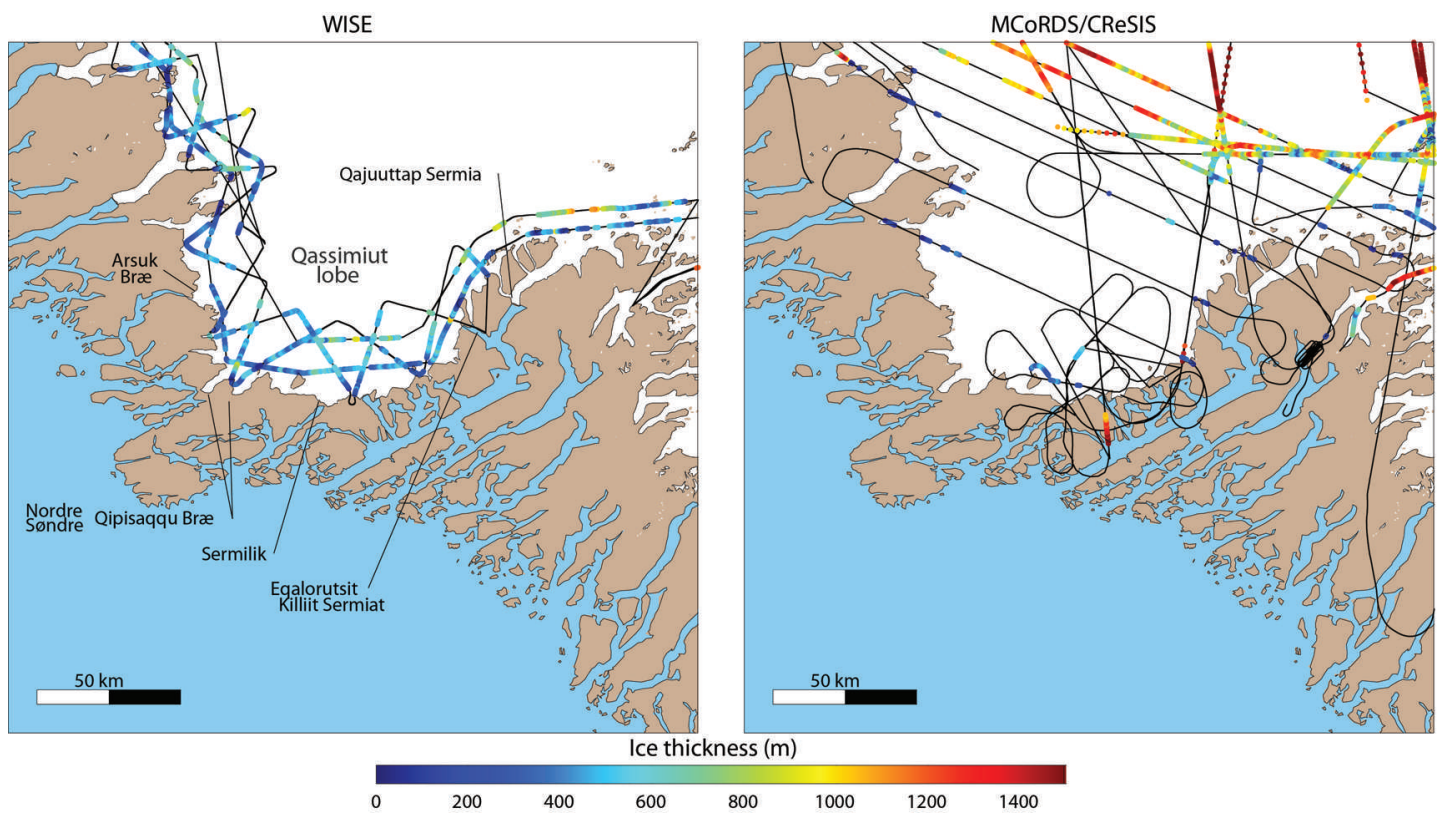

Fig. 5. Ice thickness of the Qassimiut lobe, Greenland, from WISE (left) during three campaigns conducted in 2008, 2009 and 2010 and from 1993-2013 MCoRDS/CReSIS (right). The coastline is given by Rignot (2012) and the ice edges by http://bprc.osu.edu/GDG/icemask.php.

be taken into account. These errors are nominally $\sim 5-10 \mathrm{~m}$, but could be larger in regions of rapid thinning, such as Jakobshavn Isbræ, Greenland, which thins at a rate higher than $10 \mathrm{~m} \mathrm{a}^{-1}$ (Thomas and others, 2003). Uncertainties in ice thickness also result from bed digitizing. In the case of WISE, the antenna pattern is very broad, and off-nadir reflections may be problematic, especially along narrow, steep-walled outlet glaciers found in Alaska or Patagonia. In such cases, identification of bed returns requires crossover analysis, comparison of the results with a mass-conservation approach (Morlighem and others, 2011) or comparison with a simulation of the radar returns from the surface topography alone using a simple scattering model (Nouvel and others, 2004; Mouginot and others, 2010). Finalization of the bed a

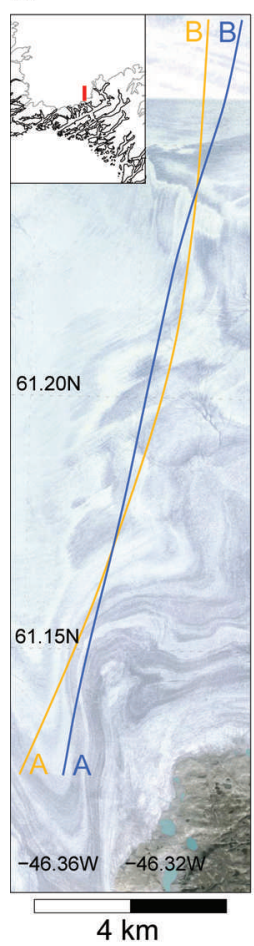

b

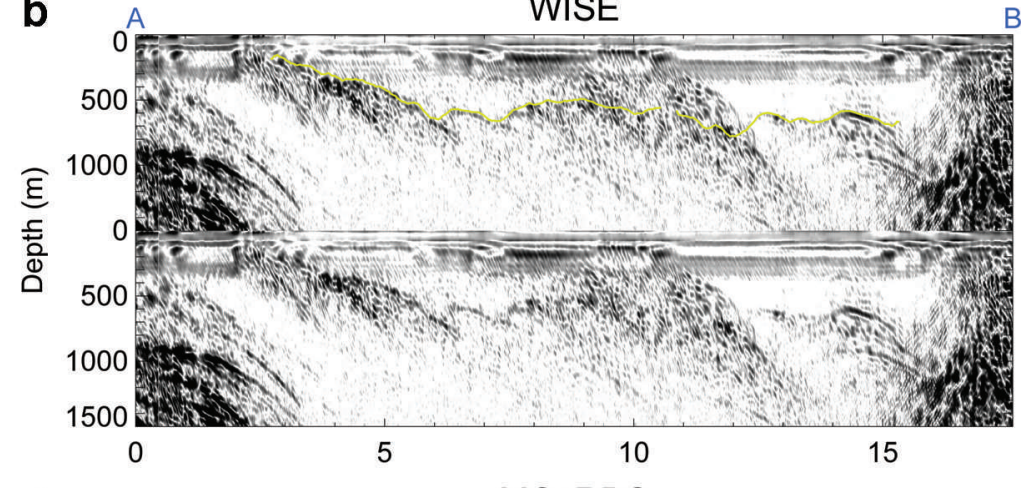

b $0^{A}$

WISE

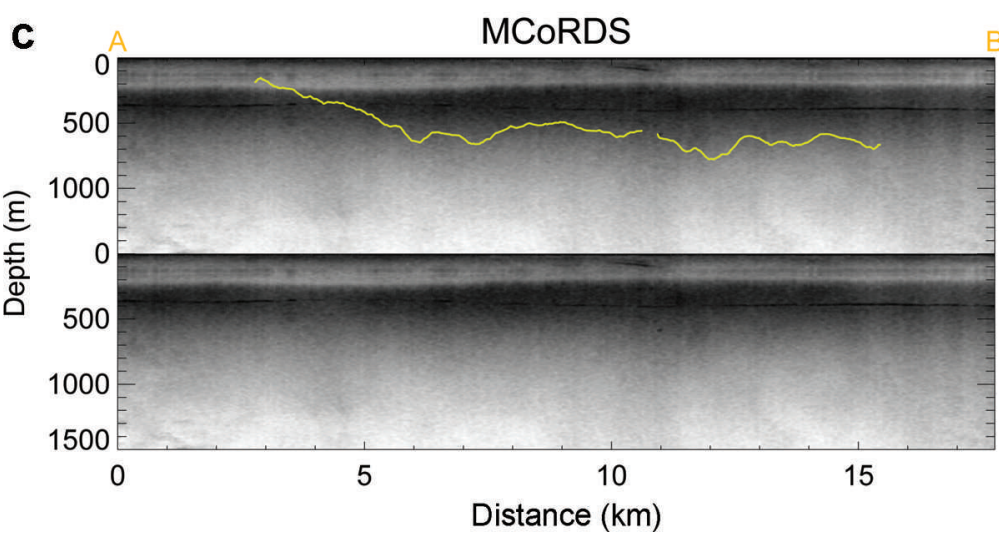

Fig. 6. (a) Flight lines of WISE (blue) and MCoRDS (orange) along the eastern side of the Qassimiut lobe. Background image is from DigitalGlobe (Google Earth). (b) Echo-radargram acquired by WISE in March 2010 at altitude $\sim 1500 \mathrm{~m}$ and a bandwidth of $2-5 \mathrm{MHz}$. The yellow line represents the digitized bed. (c) Echo-radargram acquired by MCoRDS in May 2003 at altitude $3000 \mathrm{~m}$ and a bandwidth of 140-160 MHz. The WISE digitized bed is over-plotted on the top panel. The letters A and B indicate the beginning and the end of the flight lines. 


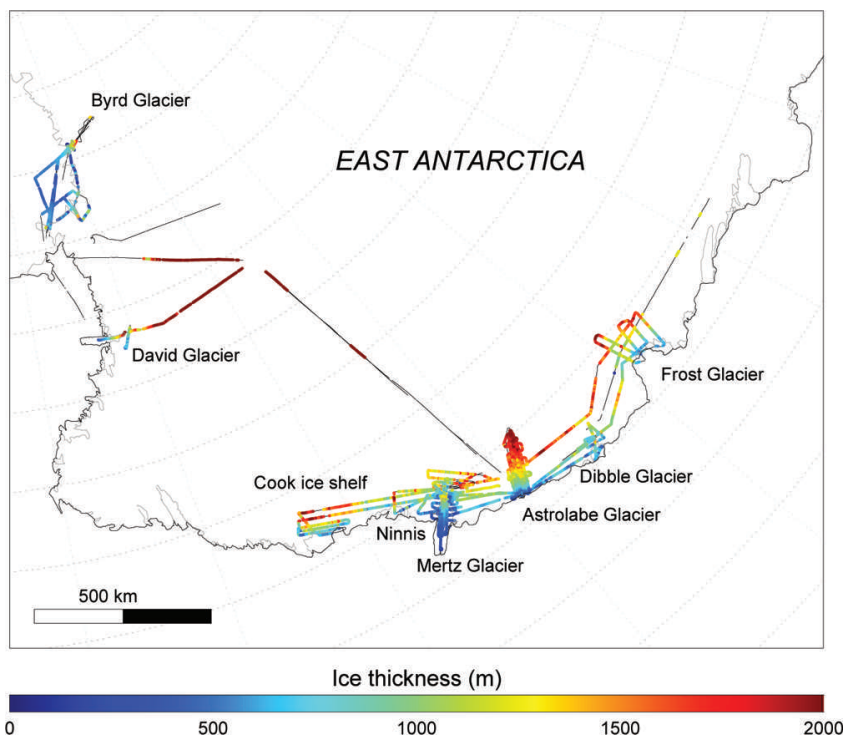

Fig. 7. Ice thickness of East Antarctica from WISE during campaigns in 2009 and 2010. Data in black indicate no bed return. Thin gray and black lines represent, respectively, the grounding line (Rignot and others, 2011) and the coastline (Rignot and others, 2013b). digitization typically involves several iterations to converge toward a stable solution.

To determine the accuracy of the digitized ice thicknesses from WISE, we compare the results with MCoRDS data on Russell Glacier, central west Greenland, and the HiCARS data on Astrolabe Glacier, East Antarctica (Fig. 8). On Russell Glacier, liquid water is likely present at many levels within the ice substrate, as manifest by the presence of many supraglacial lakes (McMillan and others, 2007). In 2010 WISE and NASA OIB/MCORDS conducted extensive grid surveys of this glacier, with track spacings of $3 \mathrm{~km}$ and $500 \mathrm{~m}$, respectively. Figure 8 shows the distribution of the difference in ice thickness between the two instruments at the crossover points. The standard deviation of the difference is $55 \mathrm{~m}$ and the mean is $-28 \mathrm{~m}$. The mean difference could result from slight differences in surface reference. The standard deviation is consistent with the expected accuracy given the sources of error described above. In this region, the accuracy of the MCoRDS radar was estimated at $\sim 34 \mathrm{~m}$, by comparison with radar tomography (Wu and others, 2011; Morlighem and others, 2013).

In East Antarctica, ice is not expected to include englacial meltwater, because it is colder and cleaner, and hence highly penetrative. We compare WISE with HiCARS over Astrolabe Glacier (Fig. 8). The standard deviation in icethickness difference is $25 \mathrm{~m}$ and the mean difference is $12 \mathrm{~m}$.
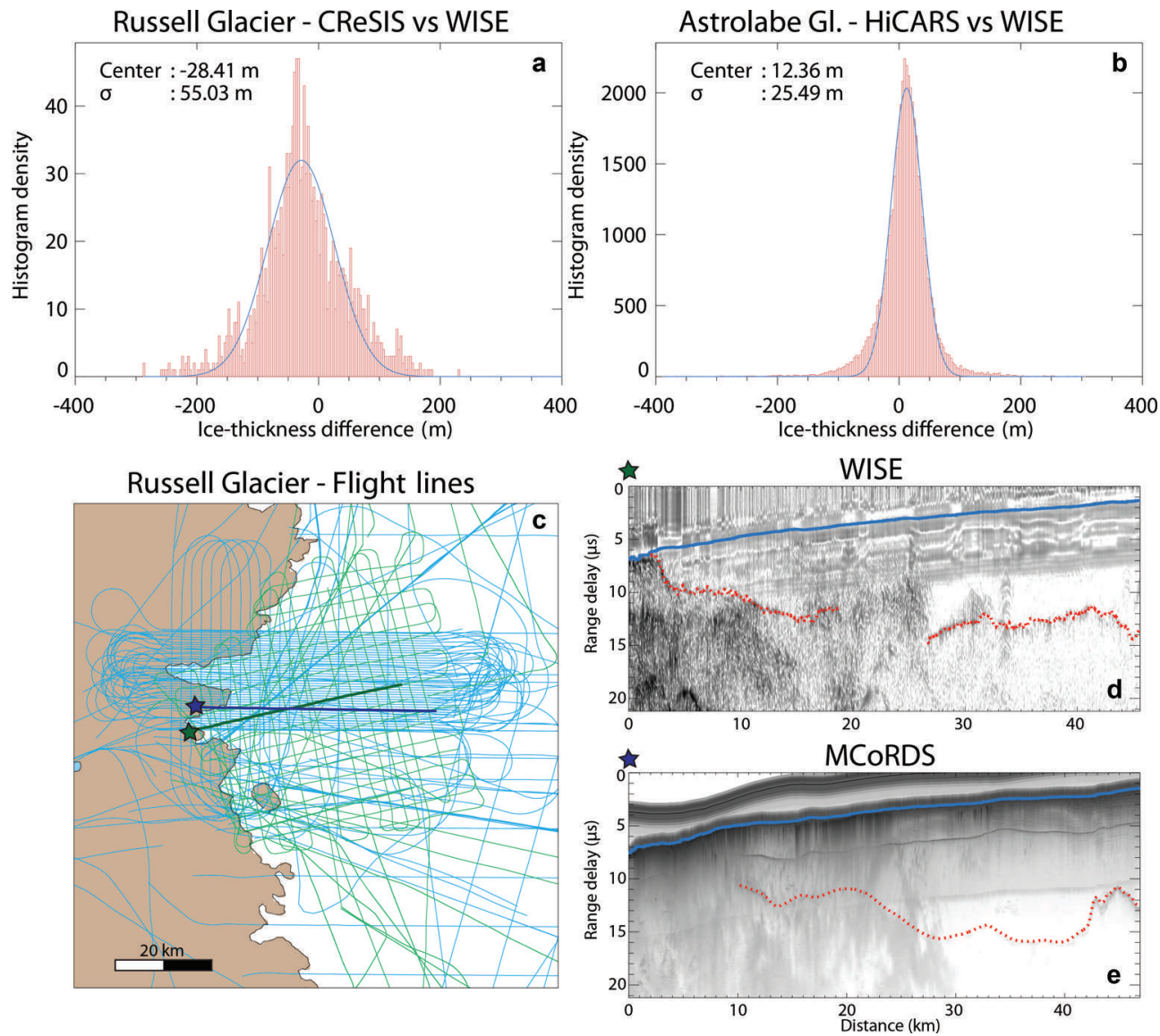

Fig. 8. (a) Crossover analysis between ice-thickness measurements from MCoRDS/CReSIS and WISE over Russell Glacier, Greenland. (b) Crossover analysis between ice-thickness measurements from HiCARS (UT) and WISE over Astrolabe Glacier, Terre Adélie, East Antarctica. The distributions (light red) of the difference in thickness for soundings are collected within $100 \mathrm{~m}$ of each other in Greenland, and $50 \mathrm{~m}$ in Antarctica. The blue lines are the Gaussian fits applied to the distributions, with the indicated mean and standard deviation. (c) Flight lines of MCoRDS/CReSIS (light blue) and WISE (light green) over Russell Glacier. (d) Echo-radargram acquired by WISE in March 2010 along the dark green line shown in (c). (e) Echo-radargram acquired by MCoRDS in April 2011 along the dark blue line shown in (c). The dark green and blue stars represent the beginning of the WISE and MCoRDS echo-radargrams. 
The level of performance measured in Greenland is likely more representative of the general capability of the system in challenging environments. A $50 \mathrm{~m}$ precision in thickness is, however, sufficient for many applications, especially considering that in several sectors discussed here higherfrequency sensors do not always provide bed returns and, where they do, the precision is $\sim 30 \mathrm{~m}$.

\section{CONCLUSION}

We have successfully retrieved ice-thickness measurements using the WISE 2-5 MHz airborne radar sounder in Greenland and Antarctica during five campaigns between 2008 and 2010. We report measurements of ice thickness at the southern tip of Greenland, in the Qassimiut lobe, an area where probing at higher frequencies is difficult, proving the ability of the WISE system to measure ice thicknesses in a highly scattering environment. We note that this achievement was possible despite many technical and operational challenges of flying such a long-wavelength radar on a fixedwing aircraft. Low-frequency radars are emerging to complement high-frequency radars, not only for temperate ice mapping but also for mapping areas traditionally considered as polar yet scattering, as is the case in southern Greenland. The WISE data from 2008-12 will be posted at the US National Snow and Ice Data Center (NSIDC) as part of NASA Operation IceBridge. Future developments for WISE include an upgrade of the PRF to $10 \mathrm{KHz}$. This will allow an increase in stacking by a factor of ten and therefore improve the signal-to-noise ratio by $10 \mathrm{~dB}$ (Wright and others, 1994).

\section{ACKNOWLEDGEMENTS}

This work was performed at the Department of Earth System Science, University of California Irvine, and at the California Institute of Technology's Jet Propulsion Laboratory under a contract with the National Aeronautics and Space Administration Cryospheric Science Program; and at the Laboratoire de Glaciologie et Géophysique de I'Environnement (LGGE) under a contract with the French polar institute, Institut PaulEmile Victor (IPEV). The Antarctic program benefited from logistical support from the IPEV through the program DACOTA-ANR-06-VULN-016-01 (funded by the Agence Nationale pour la Recherche) and the program DACOTAIPEV-1053 (funded by the IPEV). Part of the development of WISE has been funded by NASA's Planetary Instruments Definition and Development Program (PIDDP). We thank the three reviewers, Steven Arcone, John Paden and Jie-Bang Yan, and the scientific editor, Sivaprasad Gogineni, for helpful and constructive comments on the manuscript.

\section{REFERENCES}

Allen C (2010) IceBridge MCoRDS L2 ice thickness [2008-2013]. NASA Distributed Active Archive Center, National Snow and Ice Data Center, Boulder, CO. Digital media: http://nsidc.org/data/ irmcr2

Arcone SA (2002) Airborne-radar stratigraphy and electrical structure of temperate firn: Bagley Ice Field, Alaska, USA. J. Glaciol., 48(161), 317-334 (doi: 10.3189/172756502781831412)

Bamber JL, Gomez-Dans JL and Griggs JA (2009) A new 1 km digital elevation model of the Antarctic derived from combined satellite radar and laser data - Part 1: data and methods. Cryosphere, 3(1), 101-111 (doi: 10.5194/tc-3-101-2009)
Bamber JL and 10 others (2013) A new bed elevation dataset for Greenland. Cryosphere, 7(2), 499-510 (doi: 10.5194/tc-7499-2013)

Blankenship DD, Kempf SD and Young DA (2011) IceBridge HiCARS 1 L2 geolocated ice thickness [2009-2012]. NASA Distributed Active Archive Center, National Snow and Ice Data Center, Boulder, CO. Digital media: http://nsidc.org/data/ir1hi2

Bogorodsky VV, Bentley CR and Gudmandsen PE (1985) Radioglaciology. D Reidel, Dordrecht

Box JE and 8 others (2006) Greenland ice sheet surface mass balance variability (1988-2004) from calibrated polar MM5 output. J. Climate, 19(12), 2783-2800 (doi: 10.1175/JCLI3738.1)

Brown CS, Rasmussen LA and Meier MF (1986) Bed topography inferred from airborne radio-echo sounding of Columbia Glacier, Alaska. USGS Prof. Pap. 1258-G

Catania GA and Neumann TA (2010) Persistent englacial drainage features in the Greenland Ice Sheet. Geophys. Res. Lett., 37(2), L02501 (doi: 10.1029/2009GL041108)

Catania GA, Neumann TA and Price SF (2008) Characterizing englacial drainage in the ablation zone of the Greenland ice sheet. J. Glaciol., 54(187), 567-578 (doi: 10.3189/ 002214308786570854)

Conway H, Smith B, Vaswani P, Matsuoka K, Rignot E and Claus P (2009) A low-frequency ice-penetrating radar system adapted for use from an airplane: test results from Bering and Malaspina Glaciers, Alaska, USA. Ann. Glaciol., 50(51), 93-97 (doi: 10.3189/172756409789097487)

Fretwell P and 59 others (2013) Bedmap2: improved ice bed, surface and thickness datasets for Antarctica. Cryosphere, 7(1), 375-393 (doi: 10.5194/tc-7-375-2013)

Gades AM, Raymond CF and Conway HB (2012) Radio-echo probing of Black Rapids Glacier, Alaska, USA, during onset of melting and spring speed-up. J. Glaciol., 58(210), 713-724 (doi: 10.3189/2012JoG11J145)

Gogineni S and 9 others (2001) Coherent radar ice thickness measurements over the Greenland ice sheet. J. Geophys. Res., 106(D24), 33 761-33 772 (doi: 10.1029/2001JD900183)

Griggs JA and Bamber JL (2009) A new 1 km digital elevation model of Antarctica derived from combined radar and laser data - Part 2: validation and error estimates. Cryosphere, 3(1), 113-123 (doi: 10.5194/tc-3-113-2009)

Ishimaru A (1978) Wave propagation and scattering in random media. Academic Press, New York

Jacob T, Wahr J, Pfeffer WT and Swenson S (2012) Recent contributions of glaciers and ice caps to sea level rise. Nature, 482(7386), 514-518 (doi: 10.1038/nature10847)

Jacobel RW and Anderson SK (1987) Interpretation of radio-echo returns from internal water bodies in Variegated Glacier, Alaska, USA. J. Glaciol., 33(115), 319-323

Johnson AJ, Larsen CF, Murphy N, Arendt AA and Zirnheld SL (2013) Mass balance in the Glacier Bay area of Alaska, USA, and British Columbia, Canada, 1995-2011, using airborne laser altimetry. J. Glaciol., 59(216), 632-648 (doi: 10.3189/ 2013JoG12J101)

Lampkin DJ, Amador N, Parizek BR, Farness K and Jezek K (2013) Drainage from water-filled crevasses along the margins of Jakobshavn Isbræ: a potential catalyst for catchment expansion. J. Geophys. Res., 118(2), 795-813 (doi: 10.1002/jgrf.20039)

Macheret YuYa, Moskalevsky MYu and Vasilenko EV (1993) Velocity of radio waves in glaciers as an indicator of their hydrothermal state, structure and regime. J. Glaciol., 39(132), 373-384

McMillan M, Nienow P, Shepherd A, Benham T and Sole A (2007) Seasonal evolution of supra-glacial lakes on the Greenland Ice Sheet. Earth Planet. Sci. Lett., 262(3-4), 484-492 (doi: 10.1016/ j.epsl.2007.08.002)

Molnia BF (2008) Glaciers of North America: glaciers of Alaska. In Williams RS Jr and Ferrigno JG eds. Satellite image atlas of glaciers of the world. (USGS Professional Paper 1386-K) United States Geological Survey, Denver, CO 
Morlighem M, Rignot E, Seroussi H, Larour E, Ben Dhia $\mathrm{H}$ and Aubry D (2011) A mass conservation approach for mapping glacier ice thickness. Geophys. Res. Lett., 38(19), L19503 (doi: 10.1029/2011GL048659)

Morlighem $M$ and 6 others (2013) High-resolution bed topography mapping of Russell Glacier, Greenland, inferred from Operation IceBridge data. J. Glaciol., 59(218), 1015-1023 (doi: 10.3189/ 2013JoG12J235)

Mouginot J and 8 others (2010) The $3-5 \mathrm{MHz}$ global reflectivity map of Mars by MARSIS/Mars Express: implications for the current inventory of subsurface $\mathrm{H}_{2} \mathrm{O}$. Icarus, 210(2), 612-625 (doi: 10.1016/j.icarus.2010.07.003)

Mouginot J, Pommerol A, Beck P, Kofman W and Clifford SM (2012) Dielectric map of the Martian northern hemisphere and the nature of plain filling materials. Geophys. Res. Lett., 39(2), L02202 (doi: 10.1029/2011GL050286)

Nouvel J-F, Herique A, Kofman W and Safaeinili A (2004) Radar signal simulation: surface modeling with the Facet Method. Radio Sci., 39(1), RS1013 (doi: 10.1029/2003RS002903)

Picardi G and 33 others (2005) Radar soundings of the subsurface of Mars. Science, 310(5756), 1925-1928 (doi: 10.1126/ science.1122165)

Plaut JJ and 23 others (2007) Subsurface radar sounding of the South Polar layered deposits of Mars. Science, 316(5821), 92-95 (doi: 10.1126/science.1139672)

Raymond CF, Neumann TA, Rignot E, Echelmeyer K, Rivera A and Casassa G (2005) Retreat of Glaciar Tyndall, Patagonia, over the last half-century. J. Glaciol., 51(173), 239-247 (doi: 10.3189/ 172756505781829476)

Rignot E (2012) Ice flow in Greenland for the International Polar Year 2008-2009. Geophys. Res. Lett., 39(11), L11501 (doi: 10.1029/2012GL051634)

Rignot E, Mouginot J and Scheuchl B (2011) Antarctic grounding line mapping from differential satellite radar interferometry. Geophys. Res. Lett., 38(10), L10504 (doi: 10.1029/ 2011GL047109)

Rignot E, Mouginot J, Larsen CF, Gim Y and Kirchner D (2013a) Low-frequency radar sounding of temperate ice masses in Southern Alaska. Geophys. Res. Lett., 40(20), 5399-5405 (doi: 10.1002/2013GL057452)

Rignot E, Jacobs S, Mouginot J and Scheuchl B (2013b) Ice shelf melting around Antarctica. Science, 341(6143), 266-270 (doi: 10.1126/science.1235798)
Rodriguez-Morales F and 17 others (2013) Advanced multifrequency radar instrumentation for polar research. IEEE Trans. Geosci. Remote Sens., 52(5), 2824-2842 (doi: 10.1109/ TGRS.2013.2266415)

Smith BME and Evans S (1972) Radio echo sounding: absorption and scattering by water inclusion and ice lenses. J. Glaciol., 11(61), 133-146

Stolt RH (1978) Migration by Fourier transform. Geophysics, 43(1), 23-48 (doi: 10.1190/1.1440826)

Studinger M, Koenig L, Martin S and Sonntag JG (2010) Operation IceBridge: using instrumented aircraft to bridge the observational gap between ICESat and ICESat-2. In Proceedings of the International Geoscience and Remote Sensing Symposium (IGARSS 2010), 25-30 July 2010, Honolulu, HI, USA. Institute of Electrical and Electronics Engineers, Piscataway, NJ, 1918-1919

Sundal AV, Shepherd A, Nienow P, Hanna E, Palmer S and Huybrechts P (2009) Evolution of supra-glacial lakes across the Greenland Ice Sheet. Remote Sens. Environ., 113(10), 2164-2171 (doi: 10.1016/j.rse.2009.05.018)

Thomas RH, Abdalati W, Frederick E, Krabill WB, Manizade S and Steffen K (2003) Investigation of surface melting and dynamic thinning on Jakobshavn Isbræ, Greenland. J. Glaciol., 49(165), 231-239 (doi: 10.3189/172756503781830764)

Watts RD and England AW (1976) Radio-echo sounding of temperate glaciers: ice properties and sounder design criteria. J. Glaciol., 17(75), 39-48

Watts RD and Wright DL (1981) Systems for measuring thickness of temperate and polar ice from the ground or from the air. J. Glaciol., 27(97), 459-469

Wright DL, Bradley JA and Grover TP (1994) Data acquisition systems for ground penetrating radar with example applications from the air, the surface and boreholes. In Redman JL ed. Proceedings of the 5th International Conference on Ground Penetrating Radar, 12-16 June 1994, Kitchener, Ontario, Canada. University of Waterloo, Ontario, 1075-1089

Wu X, Jezek KC, Rodriguez E, Gogineni S, Rodriguez-Morales F and Freeman A (2011) Ice sheet bed mapping with airborne SAR tomography. IEEE Trans. Geosci. Remote Sens., 49(10 Pt 1), 3791-3802 (doi: 10.1109/TGRS.2011.2132802)

Young DA and 11 others (2011) A dynamic early East Antarctic Ice Sheet suggested by ice-covered fjord landscapes. Nature, 474(7349), 72-75 (doi: 10.1038/nature10114) 